\title{
Review: patients with acute low back pain and associated disability improve substantially within 1 month
}

Pengel LM, Herbert RD, Maher $C$, et al. Acute low back pain: systematic review of its prognosis. BMJ 2003;327:323-5.

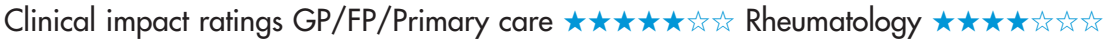

What is the natural and clinical course of acute low back pain, and what are the prognostic factors that influence this course?

\section{METHODS}

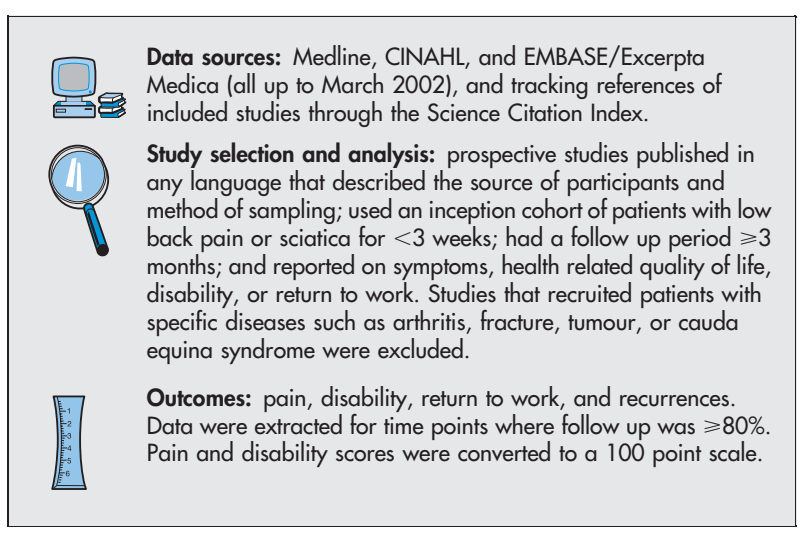

\section{MAIN RESULTS}

15 studies $(9$ randomised controlled trials, 1 controlled trial and 5 cohort studies) met the selection criteria. Of the 15 studies, only one monitored patients with sciatica. Patients were recruited from primary care (6 studies), specialists (2 studies), hospital emergency departments (6 studies), and occupational healthcare providers (9 studies). Variance weighted pooled proportions were calculated using a random effects model.

Course of low back pain. Pain decreased rapidly within 1 month (pooled mean reduction $58 \%$ of initial scores, range of study means 12-84). The pooled mean level of pain on a 100 point scale was 22 at 1 month and 15 between 3 and 12 months.

Course of disability. A similar trend was observed for disability, which decreased by a pooled mean of $58 \%$, range $33-83$, of initial levels in 1 month. The pooled mean level of disability on a 100 point scale was 24 at 1 month and 14 between 3 and 6 months. A pooled estimate of $82 \%$ ( $95 \%$ CI 73 to 91 ) of patients, initially off work,

For correspondence: Dr R D Herbert, University of Sydney, Lidcombe, NSW, Australia. R.herber+@fhs.usyd.edu.au

Sources of funding: National Health and Medical Research Council, Australia and Australasian Physiotherapy Low Back Pain Trial Consortium. returned to work within 1 month. This estimate increased to $93 \%$ (CI 91 to 96 ) at 3-6 months of follow up. The cumulative risk of $\geqslant 1$ recurrence within 12 months varied from $66-84 \%$ (pooled estimate $73 \%$, CI 59 to 88). In 1 study that included patients with sciatica, both back pain and leg pain decreased, on average, by $69 \%$ and disability by $57 \%$ of initial scores within 1 month. l study reported that Vermont disability prediction questionnaire scores $\geqslant 0.48$ were associated with return to work at 3 months (odds ratio 76, CI 9.6 to 605 )

\section{CONCLUSIONS}

Patients with acute low back pain and associated disability improve rapidly within 1 month. Further improvement is apparent until about 3 months. However, pain and disability remain ongoing and recurrences are common.

\section{Commentary}

The meta-analysis by Pengel et al provides practitioners with a strong evidentiary basis to appropriately counsel their patients with acute low back pain. Patients should be counselled that (1) their prognosis for relief of pain and return to normal activities is very favourable, with most patients initially off work returning to work within 1 month; (2) most patients who do not return to work within 1 month will do so within 6 months; and (3) residual symptoms and recurrences are common. Such education has been shown to reduce fear avoidance beliefs in patients with back pain and, in a subset of patients, to improve functional outcomes. ${ }^{1}$ These data reinforce the approach to acute low back pain articulated in the 1994 Agency for Health Care Policy and Research Clinical Practice Guidelines. ${ }^{2}$ Because only one of the included studies dealt with patients with sciatica, it is premature to conclude that such patients will have the same outcomes. Recovery from sciatica may be more delayed than what has been reported in this review.

Paul Shekelle, MD, PhD

General Internal Medicine Greater Los Angeles Veterans Administrative Health Care System Santa Monica, California, USA

1 Burton AK, Waddell G, Tillotson KM, et al. Information and advice to patients with back pain can have a positive effect. A randomized controlled trial of a novel educational booklet in primary care. Spine 1999;24:2484-91.

2 Bigos S, Bowyer O, Braen G, et al. Acute low back problems in adults. Clinical Practice Guideline No. 14. AHCPR Publication no 95-0642. Rockville, MD: Agency for Health Care Policy and Research, Public Health Service, US Department of Health and Human Services, 1994. 